\title{
The future and great challenge of HIV/AIDS psychiatry: a blending of medicine and psychiatry in a model of unified care
}

\author{
Francisco Fernandez' and Harold W. Goforth ${ }^{2,3 *}$ \\ ' Department of Psychiatry, University of South Florida, Tampa, FL, USA \\ 2 Psychiatry and Behavioral Sciences/Geriatric Psychiatry, Duke University Medical Center, Durham, NC, USA \\ ${ }^{3}$ Departments of Psychiatry and Geriatric Research Education and Clinical Center, Durham Veterans Affairs Medical Center, Durham, NC, USA \\ *Correspondence: harold.goforth@duke.edu
}

The AIDS pandemic ranks among the most devastating public health catastrophes in human history, one whose full impact has yet to be realized (Anthony and Fauci, 2008). Today there is no end in sight. Globally, a staggering 33-60 million people are estimated to be living with HIV/AIDS (UNAIDS, 2008). Each year approximately 2.7 million more people worldwide become infected with HIV and 2 million die of AIDS. In the U.S., the data is equally staggering. Over one million people are estimated to be living with HIV/AIDS. In 2007, approximately 56,300 people were newly infected (Hall et al., 2008). Epidemic trends also highlight the continued and increasing spread of the HIV virus among special populations, including women, members of minority communities, children, and older adults (Centers for Disease Control and Prevention, 2007). The devastation caused by AIDS has surpassed even the most dismal predictions of the early 1980s. Yet, no statistics, however alarming, can adequately convey the suffering and human trial these numbers represent.

The involvement of psychiatrists in the diagnosis and treatment of AIDS and HIV infection is essential, as this disease binds both internal medicine and psychiatry together like few other diseases have the potential to do. The course of HIV infection is associated with a variety of emotional, cognitive, and neurological disturbances which may be caused by premorbid psychiatric disorders; psychological stress, opportunistic infections or neoplasms; or by medications used in the treatment of HIV. Clinical experience and research also provide substantial evidence that HIV directly infects the brain soon after initial infection, which can result in central nervous system (CNS) impairment. HIV has been described as "a neuropsychiatric disease with systemic manifestations" (Ferrando and Freyberg, 2008) whose assault on the brain and human body requires the participation of both psychiatrists and internists throughout the course of illness. Missed diagnoses by inadequately trained providers can lead to irreversible damage.

Several important aspects of HIV care and treatment place those with a combined understanding of internal medicine and psychiatry at the forefront of this epidemic, including, but not limited to: (1) psychiatric disorders can increase an individual's risk of acquiring sexually transmitted diseases, including HIV (Ramrakha et al., 2000); (2) pre-existing mental disorders (including substance abuse) can predate and/or complicate HIV-related illness (Cournos et al., 2001); (3) neuropsychiatric complications and psychiatric illness can affect adherence to antiretroviral therapy regimens (Farber and McDaniel, 1999); (4) new antiretroviral treatments and combination therapies can affect the CNS and/or contribute to the development of psychiatric side effects/symptoms (Tantisiriwat et al., 1999); (5) individuals with waning immunity and high viral loads may be at particular risk for the HIV-related CNS complications that can cause acute mental status changes (Álvarez-Segura et al., 2008); (6) the proportion of mental health and/or substance abuse disorders among people living with HIV/AIDS is nearly five times greater than the proportion found in the general population (Bing et al., 2001); (7) persons living with a severe mental illness (SMI) are disproportionately vulnerable (as high as 23\%) to infection with HIV and other sexually transmitted diseases (Weiser et al., 2004); (8) racial and ethnic minorities, who bear a disproportionately higher burden of HIV, suffer disproportionately from mental disorders; (Hall et al., 2009) (9) psychiatric syndromes can be especially challenging to recognize and accurately diagnose in the medically ill (Harold et al., 1998); and (10) as HIV/AIDS is becoming an increasingly chronic disorder with the improvement of treatments and longer survival times.

It is essential, therefore, that psychiatrists receive comprehensive education in the direct care and support for the HIV patient. Psychiatrists must be prepared to manage the complex medical issues that may lead to CNS dysfunction, assess and monitor patients for the neuropsychiatric consequences of HIV, aggressively treat substance abuse and other psychiatric disorders, manage the co-administration of psychotropic drugs and antiretroviral agents, review antiretroviral regimens for agents that cause CNS side effects; facilitate the appropriate care of HIV patients with severe mental illness, promote treatment adherence, and respond to complex ethical and medical issues. And as the epidemic changes demographically, physicians will need to play an important role in managing the needs of specific patient populations, including women, adolescents, gay, lesbian, bisexual, and transgender (GLBT) people, racial and ethnic minorities, and older adults. Finally, physicians must also be prepared for challenges that accompany clinical advances and the introduction of highly active antiretroviral therapy (HAART). Potent antiretroviral regimens and combination therapies have shown tremendous advances in improving systemic health, but a similar reduction specifically in HIV-1 associated neurocognitive impairment has not been noted. These issues bind practitioners of multiple medical specialties including psychiatry, internal medicine, and neurology-and competent practitioners in HIV-AIDS medicine must be comfortable with a knowledge base that transcends any one particular specialty. 
Hope is in the air for integrating both HIV/AIDS medicine and HIV/AIDS behavioral health. The old adage "Mens sana in corporae sanae" (a sound mind in a sound body) still holds true for HIV/AIDS - in fact, it is true for all health issues. This is our goal with Frontiers in HIV and AIDS in Psychiatry - to bring about transforma- tional change in HIV/AIDS care that seeks to incorporate knowledge from multiple medical specialties into a new paradigm of care for HIV seropositive patients.

\section{REFERENCES}

Álvarez-Segura, M., Villero, S., Portugal, E., Mayoral, M., Montilla, P., and Fraguas, D. (2008). Psychosis induced by decreased $\mathrm{CD} 4++\mathrm{T}$ cell and high viral load in human immunodeficiency virus infection: a case report. Biol. Psychiatry 64, e3-e4.

Anthony, S., and Fauci, M. D (2008). 25 Years of HIV. Nature 453, 289-290.

Bing, E. G., Burnam, M. A., Longshore, D., Fleishman, J. A., Sherbourne, C. D., London, A. S., Turner, B. J., Eggan, F., Beckman, R., Vitiello, B., Morton, S. C., Orlando, M., Bozzette, S. A., OrtizBarron, L., and Shapiro, M. (2001). Psychiatric disorders and drug use among human immunodeficiency virus-infected adults in the United States. Arch. Gen. Psychiatry 58, 721-728.

Centers for Disease Control and Prevention, (2007). Cases of HIV infection and AIDS in the United States and dependent areas. HIVAIDS Surveill Rep. 19, 1-62.

Cournos, F., McKinnon, K., and Rosner, J. (2001). HIV among individuals with severe mental illness. Psychiatr. Ann. $31,50-56$.

Farber, E. W., and McDaniel, J. S. (1999). Assessment and psychotherapy practice implications of new combination antiviral therapies for HIV disease. Prof. Psychol. Res. Pr. 2, 173-179.

Ferrando, S. J., and Freyberg, Z. (2008). Neuropsychiatric aspects of infectious diseases. Crit Care Clin. 24, 889-919.

Hall, H. I., Geduld, J., Boulos, D., Rhodes, P., An, Q., Mastro, T. D., Janssen, R. S., and Archibald, C. P. (2009). Epidemiology of HIV in the United States and Canada: current status and ongoing challenges. J. Acquir. Immune. Defic. Syndr. 51, S13-S20.

Hall, H. I., Song, R., Rhodes, P., Prejean, J., An, Q., Lee, L. M., Karon, J., Brookmeyer, R., Kaplan, E. H., McKenna, M. T., and Janssen, R. S. (2008). Estimation of HIV incidence in the United States. JAMA 300, 520-529.

Harold, E., Bronheim, M. D., George Fulop, M. D., Elisabeth, J. Kunkel, M.
D., Philip, R., Muskin, M. D., Barbara, A., Schindler, M. D., William, R., Yates, M. D., Richard Shaw, M. D., Hans Steiner, M. D., Theodore, A., Stern, M. D. and Alan Stoudemire, M. D. (1998). Practice guidelines for psychiatric consultation in the general medical setting. Psychosomatics 39, S8-S30.

Ramrakha, S., Caspi, A., Dickson, N., Moffitt, T. E., and Paul, C. (2000). Psychiatric disorders and risky sexual behavior in young adulthood: crosssectional study in birth cohort. BMJ 321, 263-266.

Tantisiriwat, W., Tebas, P., Clifford, D. B., Powderly, W. G., and Fichtenbaum, C. J. (1999). Progressive multifocal leukoencephalopathy in patients with AIDS receiving highly active antiretroviral therapy. Clin. Infect. Dis. 23, 1152-1154.

UNAIDS (2008). Report on the Global AIDS Epidemic. Joint United Nations Programme on HIV/AIDS. World Health Organization. http://data. unaids.org/pub/GlobalReport/2008/
JC1510_2008GlobalReport_en.zip. Accessed 07 April 2010.

Weiser, S. D., Wolfe, W. R., and Bangsberg, D. R. (2004). The HIV epidemic among individuals with mental illness in the United States. Curr. HIV/AIDS Rep. 1, 186-192.

Received: 05 January 2010; accepted: 02 February 2010; published online: 10 May 2010.

Citation: Fernandez F and Goforth HW (2010) The future and great challenge of HIV/AIDS psychiatry: a blending of medicine and psychiatry in a model of unified care. Front. Psychiatry 1:6. doi: 10.3389/ fpsyt.2010.00006

This article was submitted to Frontiers in Neurodegeneration, a specialty of Frontiers in Psychiatry.

Copyright $\odot 2010$ Fernandezand Goforth. This is an open-access article subject to an exclusive license agreement between the authors and the Frontiers Research Foundation, which permits unrestricted use, distribution, and reproduction in any medium, provided the original authors and source are credited. 